\title{
EVENT
}

\section{A Representative Book of the Romanian Economic Scientific Greation}

Prof. Nicolae Istudor, PhD, Rector, The Bucharest University of Economic Studies, Romania.

On December 12, 2019, the "Victor Slăvescu" Prize was awarded to the book "Drafting, editing and publishing a scientific paper. An approach in the context of the economic research", the $2^{\text {nd }}$ edition, 2017, on the occasion of awarding the Romanian Academy* prizes for 2017.

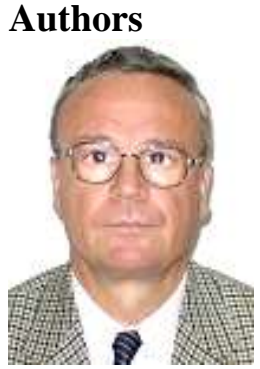

Prof. Vasile Dinu, PhD,

Editor in Chief,

Amfiteatru

Economic Journal

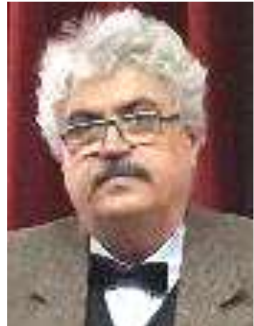

Prof. Gheorghe Săvoiu, PhD, Associate Editor, Amfiteatru

Economic Journal



Prof. Dan

Cristian Dabija,

PhD,

Associate Editor,

Amfiteatru

Economic Journal

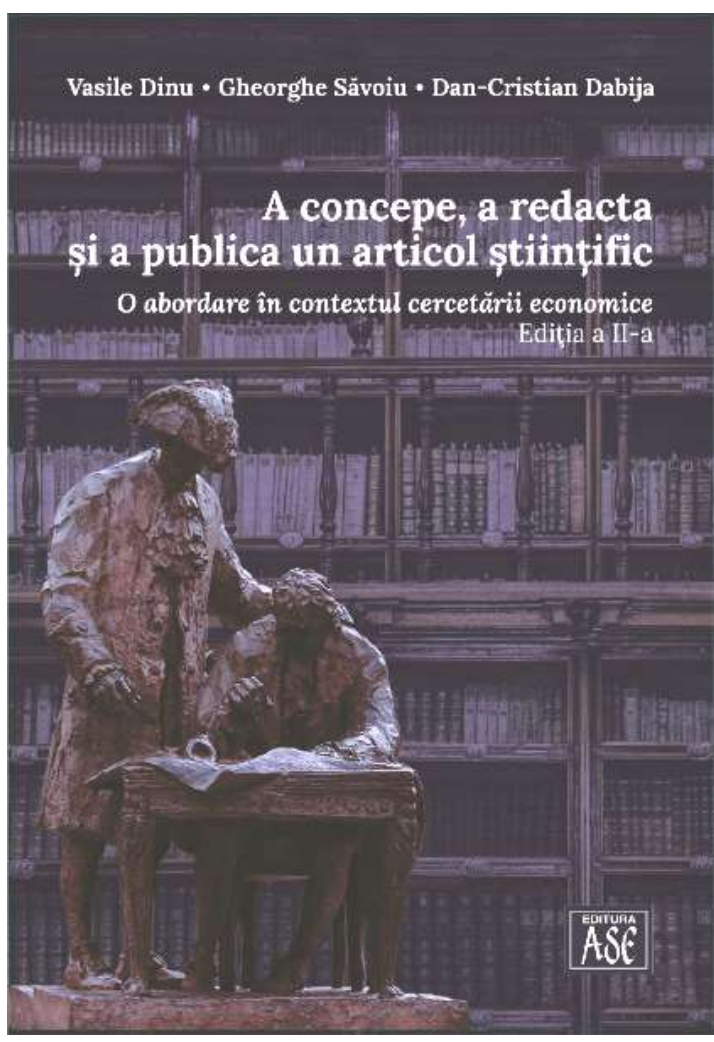

* The award list of the Romanian Academy for 2017 (It is awarded in Section XI. Economic, legal and sociological sciences) https://academiaromana.ro/premiileAR/liste/2017.pdf

The film of awarding the prizes (On minute 53, the prizes of Section XI. Economic, legal and sociological sciences begin to be awarded, and on minute 55 , one can see the authors' awarding.

https://www.youtube.com/watch?v=luN2Ym6n2jk\&feature=share\&fbclid=IwAR2iwu6_bv26REQnOmKlwqJzrC9qq93GsVuGvqqWb8T9QtPqPQezG1ADXQ 


\section{Important data}

Publishing house: ASE Bucharest

Scientific field - economics

Number of pages -457

The book structure:

- Argument;

- Foreword;

- Table of contents;

- Chapters:

- Economic research and communication of its results, in the general context of the scientific research;

- Structure and optimization of citing a scientific paper;

- Editing a scientific paper;

- Plagiarism, anti-plagiarism legislation and ethics of research;

- Assessment of scientific performance in the economic academic environment;

- International databases from the field of economics;

- Relevant criteria in the selection of scientific journals in the field of economics.

- Table of contents (English, French and German);

- Bibliography for each chapter.

\section{The actuality of the subject}

The book was released as a reply to the highly important academic debates within the last years concerning the fulfillment of the promotion criteria of the academic teaching staff and researchers, namely the necessity to publish some articles which would correspond to the European scientific demands of the field. During the last period, novelty elements had been brought to the foreground, such as: journals from the mainstream of publications (mainstream journals), impact factor, absolute influence score, the Hirsch index (H-index), the scientific papers issued in internationally acknowledged journals which have a high share within the promotion criteria. Furthermore, the present book also replies to the actuality desideratum of the Romanian academic environment concerning the introduction in the curricula of some courses on how to write scientific papers, which had already been long included in the curriculum of the foreign valuable universities. At the same time, this work meets some highly actual demands of the Romanian academic education concerning the ethics in the field of research.

Innovation or novelty, as a defining aspect of the book's appearance, is represented by the synergist result of the scientific, didactic, but also administrative expertise of the authors (editors of the Economic Amphitheatre economic journal, a journal from the mainstream of publications, indexed and quoted by the Web of Science). The three authors have understood the challenges, deficiencies, difficulties and, sometimes, shortcomings, both conceptually but especially methodologically, faced by different researchers, especially the young 
ones (master and doctoral students, teaching assistants, etc.), but not only, in drafting, editing and publishing scientific articles in the field of economics and business administration. Therefore, by this present book, its authors intended to offer to all of them a compendium of good practices in drafting, editing and publishing an economic scientific article.

Another topical issue which has also preoccupied the authors is the diminishing of a certain gap between the emerging countries (such as Romania) and the economically developed ones, which is also significantly affected in terms of visibility and dissemination of the economic research results, because one of the causes of this state of affairs lies in the more modest habilitation of those involved in research concerning the manner of drafting, editing and publishing scientific articles.

\section{Book goal}

The book authors intended, from the very beginning, to limit their analysis of the subject to the requirements of a scientific article. The issue of larger works such as treaties, monographs, textbooks, etc. is not deliberately addressed. The reason for this delimitation is required by the precise setting of the book destination. Leaning on international and national regulations in the field of scientific performance evaluation of economic research, the authors emphasize the leading role played by scientific articles in assessing researchers, to the detriment of larger scientific works.

The book authors systematically approach the process of drafting, editing and publishing a scientific paper, through a logical approach, starting from the classical and modern challenges of the current economic scientific research, passing on to the description of the structural elements of a scientific article and of the requirements regarding its editing, then presenting relevant aspects concerning the ethics of research and publication, in order to finally refer to the modalities of dissemination of the results of the carried out investigations. The purpose of this approach is to provide practical suggestions for improving the work of elaboration and publishing the scientific articles.

The book addresses a large, but well-structured audience, from the section of the bachelor's level to the master's level students, from doctoral students to researchers and teaching staff in the field of economics and business administration, in a word, the entire higher education staff in the field, interested in the effective dissemination of the fruits of the undertaken research. If concerning the target audience categories, there is a clearly defined addressability on a national level, by the fact that the book has a content and a summary in English, French and German, can also arouse the interest of researchers in the field of economics from the countries of Central and Eastern Europe.

\section{General objective}

The book is intended mainly for young researchers, doctoral students, master and BA students, but also for academic teaching staff interested in the elaboration and publication of scientific articles in prestigious journals from the mainstream of 
publications, indexed and quoted in databases relevant to the international scientific community. Its main objective is to bring to the fore a series of good practices in drafting, editing and publishing a scientific article for the field of economics and business administration, concerning the following aspects: the stages of the process of elaborating an economic scientific paper; the technical, but also the formal aspects which must be considered when effectively writing a paper; the means of disseminating information by selecting the most representative economic scientific journals according to different criteria and by correlating them with the current system of academic economic performance, and by selecting the representative criteria for choosing the relevant economic scientific journals.

\section{Originality}

The originality of the paper resides in the integrated and synergistic presentation not only of the aspects related to drafting, editing and publishing a scientific article, but also of those concerning: the efficient way of communicating the results of the scientific research; ethics of research, plagiarism and concrete methods of identifying and preventing it; highlighting the criteria for choosing journals for publication; means to optimize citations in order to increase the scientific performance. The present book is an original endeavour, being one of the pioneering works in the field of economics in Romania.

\section{Book structure}

Each of the seven chapters of this book addresses a distinctive theme in the process of searching the truth, through scientific research, until its transposition on the page, in the manner required by a perfect professional ethics.

In order to inscribe the thematic object of this book - the economic research in the general context of the scientific approach, the first chapter of the book is dedicated to the typological structure and the particularities of the modern economic research. We consider it important to point out the optics in which the authors treat the contemporary economic scientific research, marked by inter- and multidisciplinarity. It is due to the paradigm shift in the approach of economic processes and phenomena, from a unilateral type of approach to an integrative one. The role of measuring phenomena and of the validity of theory as essential components of the economic research is also worth mentioning.

The key terms specific to an economic research approached on four successive cycles of investigation occupy a distinct and well-defined place. This concern for terminological clarifications helps the reader to correctly interpret the working toolbox used throughout the entire book. Being aware of the significance of communication to the process of disseminating the results of scientific research in the field, the authors have dedicated it a consistent part of the book, being treated both conceptually and especially operationally, in order to come to the support of the approved reader.

The second chapter of the book starts from the morphology of the structural components of a scientific article, grouped into pre-text elements (title, authors, keywords, JEL classification), text elements (introduction, body of the article, results, 
discussions) and post-text elements (conclusions, bibliography, annexes). The scientometric criteria for evaluating a scientific article are then extensively treated in order to optimize the citation of such a material, which supports its dissemination. The large international databases are brought to the foreground (Clarivate Analytics, former Thomson Reuters, within the Web of Science and Elsevier in Scopus), highlighting the significance of the Hirsch index for international recognition of the value of a scientific article. The whole approach is customized as an example for the field of economics and business administration.

The editing of the scientific article represents the body of the third chapter of this book. The recommendations for the scientific editing style, accompanied by numerous examples, are continued with those for editing the bibliography. Noteworthy is the distinction, which is required, between the list of references and the bibliographical list. The clarifications regarding the citation methods: authornumber and author-date system (the Harvard system), through the used exemplifying details, cover the entire range of situations encountered in the economic literature. The distinction between citation methods is also made in a scientific article and, respectively, in a communication at a scientific conference. The chapter is completed with useful techo-editing rules.

One topic which kindles debates on the ethics of research is that of plagiarism and anti-plagiarism legislation, to which the authors dedicate the fourth chapter. The problem of the protection of intellectual property is essential in the postmodern world, in which the danger of collage is present. Cutting from multiple places "quoting correctly" and putting things together leads to obtaining a "true" literature review, but not to an original scientific paper. Paying attention to the phenomenon of plagiarism and its precursor - the similarity - an approach is being made in the direction of the ethics of scientific research.

The semantic paradigm of plagiarism in research is debated, not only conceptually but also typologically. Cases of common knowledge are also treated, which annul the accusation of plagiarism. But the authors' faith in the original expression and the consequence with which they militate for the respect of original ideas is thus significant. The incursion, in a historical shade, into the anti-plagiarism legislation adequately completes the approach headed towards the protection of the intellectual property. The fact that the chapter presents the typological diversity of situations from plagiarism per se to auto-plagiarism, from institutional autoplagiarism to cryptomnesia, only familiarizes the reader with the variety of situations which can occur when editing a scientific article and implicitly with the need to avoid them. The casuistic multitude also helps here in a clearer understanding of each situation in part. The methods and means of preventing and avoiding plagiarism happily conclude this chapter.

Chapter five is dedicated to the assessment of scientific performance in the Romanian economic academic environment, an extremely relevant and representative phenomenon. It is the place which opens the perspective of very actual debates on the assessment of scientific performance in the economic academic environment. They demand to contribute to the necessary mutation, an aspect previously highlighted within this presentation, and namely, passing on, with more courage, from the 
quantitative to the qualitative assessment of the academic performance. The critical aspects signalled by the authors are accompanied by an ample exemplifying material. Neither the spiny issue of financing the economic scientific research, nor the low receptiveness of the business environment in getting involved in this process, in mutually advantageous conditions, is avoided. The assessors' character of full impartiality is neither overlooked.

Chapter six is dedicated to approaching the representative databases for economics, which contribute to the indexation of the scientific journals. The monographic approach of this aspect is represented in a significant orientation method of the researcher, who wishes to valorize the fruit of his/her own investigations. In the same approach style, the method of establishing a journal's scientific style will be subjected to debate, so that the author disposes of the necessary information in achieving the best option in order to publish his/her own material. The method of calculating the scientometric indicators, of the most important international databases, help the reader in the choice he/she is going to make.

The last chapter of the book ends with the analysis of the relevant criteria in choosing an economic scientific journal. From the journal's visibility to the costs associated with publication, from the journal's or any number of the journal's thematic specificity the total time span before its publication, and many other elements, allow the reader to accomplish a radiography of the factors he/she is requested to keep in mind when deciding to publish a scientific article.

We underline the consistency of the bibliographical support, which accompanies every chapter, representing a guide for valuable documentary resources.

\section{Conclusions}

The triple idea of uniqueness, necessity and opportunity of this book remains correlated with the systematic effort undertaken by the authors in order to present the complex research in economics with simplicity and in easily understandable terms, namely with varied practical examples which raise its utilisation value. The reader may find and successfully use the ampleness of the presented ideas, explanations and examples, which perfectly integrate themselves into a logic and a coherence specific to the rational, lucid and creative approach of the valuable scientific papers.

As a final remark, the applicative creativity, the structural optimization and the realistic anticipation of the opportunity of this book should be emphasized, at the same time with the authors' fulfilled desire to present, with simplicity and in an easily understood language, the essential aspects related to the elaboration of a scientific article, interesting by content and attractive as a form of presentation, therefore with increased chances of being accepted and published in a prestigious journal from the mainstream of economic publications (mainstream economics journals). Those readers, especially researchers and university professors, but especially the young researchers in the field of economics and business administration who aim at the scientific consecration, have in front of them a pragmatic and, at the same time, a useful work for everybody. 